\title{
Exploiting the natriuretic peptide system for the treatment of pulmonary hypertension Adrian J Hobbs*
}

\author{
Address: University College London, London, UK \\ Email: Adrian J Hobbs* - a.hobbs@ucl.ac.uk \\ * Corresponding author
}

\author{
from $3^{\text {rd }}$ International Conference on cGMP Generators, Effectors and Therapeutic Implications \\ Dresden, Germany. 15-17 June 2007 \\ Published: 25 July 2007 \\ BMC Pharmacology 2007, 7(SuppI I):S7 doi:I0.II86/I47I-2210-7-SI-S7
}

This abstract is available from: http://www.biomedcentral.com//47I-22/0/7/SI/S7

(c) 2007 Hobbs; licensee BioMed Central Ltd.

\section{Introduction}

Pulmonary hypertension (PH) is characterised by increased pulmonary arterial blood pressure, vascular remodelling of the small pulmonary arteries, right ventricular hypertrophy and ultimately right ventricular failure. Whether idiopathic (primary PH) or secondary (due to chronic lung disease, congenital heart disease or HIV infection), the disease carries a high mortality and morbidity, primarily because of the lack of selective pulmonary vasodilators. Current treatment options include prostacyclin analogues (e.g. epoprostenol) and the endothelin receptor antagonist bosentan; however, these agents suffer from many drawbacks including the need for parenteral administration and, like other vasodilators (e.g. calcium channel blockers), have significant systemic hypotensive effects. Recently, the phosphodiesterase 5 (PDE V) inhibitor sildenafil has been licensed for the treatment of PH. Sildenafil is orally active, has selective pulmonary vasodilator effects and improves exercise tolerance in patients with $\mathrm{PH}[1]$, thus representing a significant advance over existing therapy. In addition, attention has focused on novel combination therapies for PH (e.g. sildenafil plus iloprost) [2] or by increasing cGMP levels by activating soluble guanylate cyclase (sGC; e.g. inhaled NO, BAY 41-2272) [3].

The mechanism(s) underlying the pulmonary selectivity of sildenafil remain unclear. Although sildenafil reduces functional and structural changes in many animal models of $\mathrm{PH}$, the pulmonary selectivity of sildenafil is blunted in animals lacking the natriuretic peptide receptor (NPR)-A [4]. This suggests that the mechanism of pulmonary selectivity of PDE V inhibition is dependent, at least in part, on the bioactivity of natriuretic peptides and activation of the particulate isoform of guanylate cyclase. Thus, we have explored the interaction(s) of PDE V inhibitors and the natriuretic peptide system in vitro and in vivo, including an animal model of $\mathrm{PH}$, to more fully elucidate the (patho)physiological relationship between these two cGMP-regulating systems.

\section{Results}

Using classical organ bath pharmacology to assess the reactivity of isolated aortic and pulmonary artery smooth muscle from the rat, we observed that sildenafil augments relaxations to the NO-donor, spermine NONOate, in both vessel types. In marked contrast, sildenafil only enhances the vasodilator activity of atrial natriuretic peptide (ANP) in the pulmonary artery. Furthermore, the in vivo hypotensive effect of ANP is augmented by sildenafil specifically in the pulmonary resistance vasculature. These data suggest a specific role for PDE V in the modulation of pulmonary (but not systemic) responses to natriuretic peptides in the mouse in vitro and in vivo. This gives rise to the possibility of effecting organ- or vessel-specific alterations in the vasodilator activity of natriuretic peptides, which may represent an important physiological regulatory mechanism and may be of therapeutic benefit in PH. 
To address the latter possibility, we explored the beneficial effects of sildenafil, the neutral endopeptidase inhibitor ecadotril (prevents natriuretic peptide breakdown and thereby augments plasma levels of these peptides), and a combination of sildenafil plus ecadotril, on vascular function and pulmonary remodelling in an animal model of hypoxia-induced $\mathrm{PH}$. Our results indicate that a combination of sildenafil plus ecadotril is superior to either drug alone in reversing many indices of disease progression and severity including increased pulmonary artery pressure, right ventricular hypertrophy and pulmonary vascular remodelling. Importantly, a combination of sildenafil plus ecadotril had no significant effect on systemic blood pressure.

\section{Conclusion}

These data imply that manipulating the natriuretic peptide system can enhance the pulmonary selectivity of PDE 5 inhibitors and may offer a better means of treating $\mathrm{PH}$ than PDE V inhibitors alone or in combination with activation of the soluble isoform of GC (particularly in terms of avoiding systemic hypotension). Moreover, these findings give clear evidence for compartmentalisation of cGMP-dependent signalling between the soluble and particulate guanylate cyclases and differential regulation of cGMP metabolism by PDEs between vascular beds.

\section{References}

I. Gillies HC, Roblin D, Jackson G: Coronary and systemic hemodynamic effects of sildenafil citrate: from basic science to clinical studies in patients with cardiovascular disease. Int J Cardiol 2002, 86:|3|-|4|.

2. Ghofrani HA, Wiedemann R, Rose F, Olschewski H, Schermuly RT, Weissmann N, Seeger W, Grimminger F: Combination therapy with oral sildenafil and inhaled iloprost for severe pulmonary hypertension. Ann Intern Med 2002, I36:51 5-522.

3. Dumitrascu R, Weissmann N, Ghofrani HA, Dony E, Beuerlein K, Schmidt H, Stasch JP, Gnoth JM, Seeger W, Grimminger F, Schermuly RT: Activation of soluble guanylate cyclase reverses experimental pulmonary hypertension and vascular remodeling. Circulation 2006, I I 3:286-295.

4. Zhao L, Long L, Morrell NW, Wilkins MR: NPR-A-Deficient mice show increased susceptibility to hypoxia-induced pulmonary hypertension. Circulation 1999, 99:605-607.

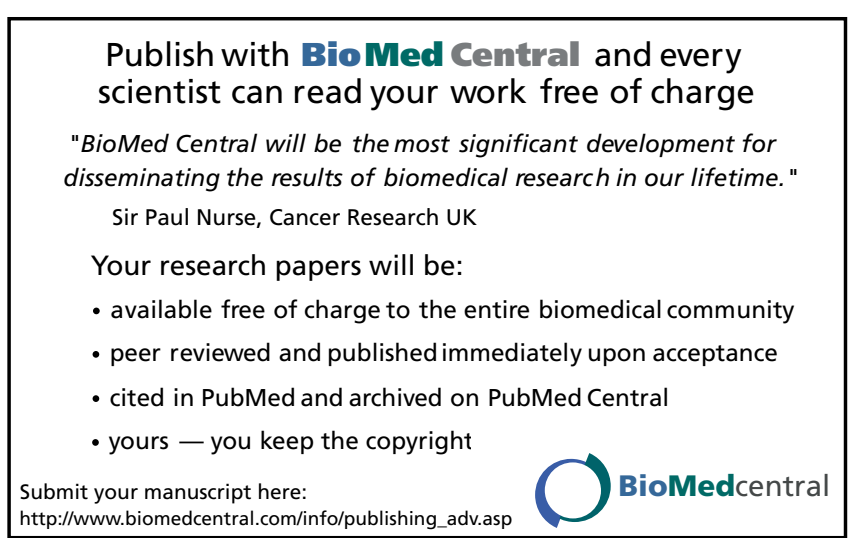

